\title{
Disney And The Magical World Of Writing; How Combining Creativity With Learning Disabilities Can Promote Academic Success
}

Michelle Janzen, Brock University, Canada

\begin{abstract}
Through a Disney perspective, this author discusses how students can use creative strategies to cope with learning disabilities in secondary, post-secondary and even graduate levels of academic achievement. In particular, the paper will be presenting how the author, who has an infinity for "everything Disney", chose to use both Disney Characters and Disney Song titles from movies and television shows, as a creative strategy in the organization of her master's research thesis. The research study entitled "Why is it so hard to go a good thing? The Paradox and Dilemma of Parental Advocacy within the Individual Education Planning Process" took a qualitative, phenomenological approach to investigate the experiences of parental advocacy and to seek out macro/micro factors that may have contributed to positive or negative outcomes within the IEP process. The author used Disney song titles as an adaptive tool not only to help in the organization of the findings of the research, but also to help illuminate the phenomenological existential themes that were revealed through the analysis. The paper hopes to demonstrate that through the use of creative strategies in otherwise conventional academic expectations, students experiencing disabilities may increase the potential of achieving academic success.
\end{abstract}

Keywords: Disney; Learning Disability; Creativity; Learning Strategies

\section{INTRODUCTION}

1 $\mathrm{n}$ a recent research study, it was found that 30-50 out of every 100 graduate students currently enrolled in graduate programming drop out before graduation (Fichton et al. 2016). In North America, over ten percent of graduate students have a variety of disabilities such as learning disabilities (LD), Attention Deficit Hyperactivity Disorder, (ADHD), mental health disorders, and other physical impairments that can often impair a student's ability to graduate from postsecondary graduate programs, and can pose unique barriers, particularly when writing their final thesis/dissertation (Fichton et al. 2016).

Learning disabilities is a general term that refers to a heterogeneous group of disorders that present deficits in acquisition and use of language, speaking, reading, writing and mathematical abilities (Luna, 2002). More specifically individuals with a learning disability often have average to above average intelligence, with deficits that may affect acquisition and retaining of information, language processing, phonological processing, visual spatial processing speed, memory and attention and executive functioning deficits (Stegemann, 2016).

Often students with learning disabilities have co-occurring disorders such as anxiety and other mental health conditions, Autism Spectrum Disorder, and most commonly Attention Deficit Hyperactivity Disorder (ADHD) (Couzens et al. 2015). These co-occurring disorders can create deficits in executive functioning, a brain system that manages cognitive processes such as flexibility, inhibition, memory, emotional control, thinking abstractly, planning, and initiating and sequencing goal directed behaviour, all of which can have a negative impact on a student's ability to achieve academic success (Grieve, Webne-Behrman, Couillou, \& Sieben-Schnieder, 2014). 
Impairments associated with learning disabilities and executive functioning processes can significantly mar a student's ability to write a thesis/dissertation, as graduate students are expected to formulate goals (such as composing and defending thesis), employ a set of strategies (such as sifting through information and material, e.g. journal articles, and one's own research material) and prioritizing and organizing this information in a way that is easy and accessible for reference when writing the thesis. Thesis writing also includes organizing ideas in a coherent manner that is easily understood, prioritizing appropriate time in order to meet given deadlines, sustaining attention and motivation during the writing process, and controlling emotional regulation during the often, frustrating process of writing (Munnawer, 2015).

In graduate programming, students with learning disabilities and other disabilities such as ADHD, and mental health disorders may also have multiple identities that they are trying to manage on top of navigating educational demands such as parenting, employment outside of their graduate work, and the responsibility to family and partners which can add on to the pressures of success in their graduate program (Beltzer \& Ross-Gordon, 2011).

While graduate thesis writing can be an endeavor in itself, it often requires students to use an orthodox format of writing with a strict structure in how the thesis should flow, starting with a literary review, followed by methodology and data analysis and ending with a discussion on the research (Hanan \& Bright, 2016). Thesis writing is a standardized process that often requires students to become a follower of the expected academic discourse, one that promotes literacy, and to do so, every student must learn to follow a specific way of thinking, perceiving and performing. McVey (2008) described that for many students who struggle with academic work such as thesis writing, students often fall into two categories; those who have difficulties with ability in writing, and those who have issues with engagement in the writing process (seeing writing as a chore, or a means to an end). These students who struggle with problems in ability and motivation are often unable to follow the expected normative writing practice, leading to the risk of finding themselves labelled as illiterate or deficient (Luna, 2002). Due to the potential for students with various disabilities to be at a greater risk for lower academic success and higher dropout rates, higher education institutions need to move away from the discourse that everyone learns and performs the same, and instead begin to allow for more creative input within typically orthodox forms of academic work to better include all students with all abilities. This paper examines the author's own experience of thesis writing and her use of incorporating Disney into her study as a learned creative strategy to compensate for her own learning issues as a way to illuminate the need for allowing flexibility within academic performance expectations for students with potential learning barriers.

\section{THEORETICAL APPROACH}

According to Susan Wendell (1996) a critical disability theorist; "disability is relative to a person's physical, social, and cultural environment". Wendell (1996) suggests that an individual's physical, medical, or neurological impairment is not necessarily disabling in itself, but rather, the specific environment that an individual finds themselves in can cause the impairment to become disabling, especially when there is lack of support or too high of demands placed on the individual. Disability is therefore socially constructed in the spaces in which people find themselves. In the context of post-secondary and graduate schooling, for students with learning impairments, disability is created in an academic setting by the failure or unwillingness of institutions to create ability through necessary accommodations for those students who do not fit the physical and mental profile of what social discourse deems as a 'paradigm citizen' (Wendell, 1996). In terms of thesis writing, disability may be created through the orthodox structure of the document, time restrictions placed on degrees and research, and pressures to submit the results of their graduate work in a written document rather than an oral presentation or other non-traditional formats of work.

Wendell (1996) further explains that as the pace of society increases, there is a tendency for more people to become disabled, especially as fewer people are able to keep up with the physical and mental expectations of "normal performance". She explains that those people who cannot keep up with the accepted pace of performance are often deemed as disabled, even though they might not have been labelled as such in a slower paced environment. In term of post-secondary and graduate programming, there is an increasing competitiveness to succeed, to push out publications, and to be engaged in multiple forms of academic projects. Individuals with learning impairments are expected to be able to keep up with the fast-paced environment of keeping up with course readings, assignments, and the intake and retention of information just as their peers without learning limitations. When these higher education institutions fail to provide the necessary accommodations such as time extensions on assignments or exams for example, their 
impairment becomes disabling, however if the same individual had been given extra time to complete an assignment or exam, the student 's learning impairment no longer becomes an issue. It is through this lens that the author addresses how current structures and organization in higher education settings are often predicated on discourses of hegemonic normalcy; academic institutions assume that every student learns in the same way and has the same ability to participate in academic life while omitting the experiences of students with various impairments creating a potentially disabling environment and barrier to academic success.

\section{BACKGROUND AND CONTEXT}

The author is currently a mature graduate student, who struggles with a number of barriers that often require employing creative strategies in order to achieve academic success. She identifies as a student on the learning disability spectrum in regard to writing, as well as having a diagnosis of ADHD, and someone who struggles with mental health issues such as anxiety. The author discovered that symptoms of these disabilities can often create barriers in an academic system that expects all instructional assessment, procedures and practices to be appropriate for all students, when in fact not all assessments, procedures and practices are appropriate or effective ways of learning for every student. On top of these already existing barriers, the author is a sole support and single mother of a child diagnosed with Autism Spectrum Disorder, who has multiple co-morbid diagnoses, which further impacts her ability to meet the often, demanding requirements of graduate programming work, research, and thesis writing.

The research undertaken by the author was a graduate master's study that took a qualitative and phenomenological approach in understanding the experiences of mothers who must advocate for their child with dual or multiple disabilities within the special education system. Throughout the process of writing the thesis, the author employed a creative strategy of using her affinity for "everything Disney" into her research (such as using Disney characters as pseudonyms, and Disney song titles used as subtitles to illuminate upcoming themes found within the findings section of her master's thesis) as a coping strategy to offset struggles associated with ADHD \& LD. This creative strategy aided the author in becoming less overwhelmed by the writing process and contributed to a means of engagement that ameliorated her potential inability to finish her master's thesis on time, while managing single parenthood of a disabled child simultaneously. Through this process she developed an approach to writing based on her love for Disney and deemed it the EPCOT approach, which allows for adding creativity into the writing process while concurrently offering an alternative coping strategy for students with different learning impairments/disabilities.

\section{Walt Disney \& EPCOT Approach to Learning}

When Walt Disney thought of the concept of EPCOT (Experimental Prototype Community of Tomorrow), he wanted to build a community, that among others, promoted future mediums that would enable a showcase for "American industry, research, schools, culture and educational opportunities" (Villmoare, \& Stillman, 2002). These promotions of research and technologies would allow for a forum in which there could be an international exchange of ideas between visitors (Chenail, 2004). However, while this idea was already ambitious, some may argue that the "real magic of Epcot lies" within its design that allows for park visitors to enjoy EPCOT in such a way that park goers could move or flow throughout the amusement park without any barriers or restrictions in their movement. A place where visitors could move seamlessly within the smaller pieces of the park (each of the world showcases, future world and technologies areas, and attractions) while still enjoying the park as a whole system (Chenail, 2004). Most importantly it enables visitors to walk away from the park with knowledge that they had previously not entered with, and who had actively participated in and engaged with the process of acquiring new learned information while simultaneously enjoying the attractions at EPCOT (Villmoare \& Stillman, 2002).

It is through this Author's affinity for Disney that she came up with the concept that learning and academic writing should be approached in the same way as how EPCOT is developed (the EPCOT approach). She established the idea that graduate thesis writing, and qualitative research can be approached and compared with the same theory that Walt Disney used designing Epcot as a type of strategy for students who may struggle with barriers in completing their thesis writing. Walt Disney's concept of EPCOT, (The EPCOT approach) can be applied to both qualitative research and graduate thesis writing. Like Epcot, qualitative research (and in particular phenomenology) aims to allow the researcher to examine the experiences of human beings as they live in the world and make sense of it, just as exploring each world showcase in EPCOT allows visitors to observe the authentic experiences of each country and culture 
featured in the world showcases, giving each visitor a unique understanding of lived experiences as they travel from one 'Country' to another (O'Grady, 2016). Through qualitative research, researchers acquire knowledge on a topic that they did not previously enter with (such as the goal of Epcot) and actively participate in the process of the absorption of that information through methods such as observation, interviews, and so forth. Qualitative research also lets the researcher to communicate ideas to the world in a format (academic publications) which permits international exchanges of ideas and understanding between others (from the author to the reader of journal article), and that enables others to share in and understand the experience of others on a global stage (just as park goers do at EPCOT). Graduate thesis writing, in the same way, needs to have an organized flow that allows for the reader to move through each of the smaller pieces of the thesis such as the design and data analysis sections while still maintaining the ability to comprehend the research as a whole (just as Epcot visitors are able to move through each small section of the park, but enjoy the overall concept of the park as a whole).

\section{Coping Strategies and the Use of Learned Creativity in Academic Writing}

Unlike Disney where imagination and creativity are key, thesis writing is often a hegemonic process that has become so conventional that it vastly limits original and creative contributions, which for some graduate students can contribute to a lack of motivation, and/or become a hindering factor in their ability to complete their graduate program. Acquiring coping skills such as developing strategies for self-regulation and organization are skills required in the postsecondary graduate environment, and for those students who face complex embodiments such as learning disabilities, mental health disorders, and outside responsibilities, this can often result in low academic performance due to an inability to adapt these skills to the educational environment. (Farmer, Allsopp, \& Ferron, 2015).

Learned creativity is a method by which individuals devise strategies or techniques as a compensatory process to better enhance their ability to perform well (Reiff, Gerber, and Ginsberg, 1993). This learned creativity can involve a multitude of various approaches to cope with meeting the demands of normative methods students are expected to use within graduate programming and thus contribute to higher rates of success. Therefore, finding creative measures (such as incorporating student interests into academic work) can be thought of as a problem-solving approach when dealing with some of these barriers. Using creativity can promote multiple options for acquiring, processing, and expressing knowledge and ultimately successful completion of graduate programming (Eladi \& Batdi, 2016).

The author used the concept of Walt Disney's EPCOT approach as well as learned creativity as a template in her qualitative research project to bring structure into the thesis writing as a coping strategy to offset anxiety, coping with ADHD and an LD, feelings of being overwhelmed during the writing process, self-regulation in the time needed for writing, and the ability to stay focused and engaged in order to meet graduation deadlines. In the author's case, incorporating her love for Disney into her thesis writing, not only was a way to incorporate learned creativity as a coping strategy in order to cope with the pressures and succeed in finishing/graduating from her Master's program, but also allowed her to stay interested and motivated to finish the final phase of completing the academic requirements necessary for her to receive her degree.

\section{BRIEF BACKGROUND AND DATA ANALYSIS OF RESEARCH STUDY}

Within the master's thesis analysis, the author took a phenomenological approach to understanding how mothers of complex children (those with dual or multiple diagnosis) advocated within the special education system. In particular the research aimed to look at what factors contributed to successful advocacy during the IEP (Individualized Education Plan) process. The study included two data sets; the first was an unobtrusive analysis of six school board websites in Ontario, both from the public and Catholic school boards, to explore the ease of access to rights-based information on the IEP process for parents; and the second data set included interviewing parents from Southern Ontario about their experiences advocating for their child within the IEP process.

The author relied on Van Manen's (1990) approach to phenomenological analysis in the parent interview analysis by taking a holistic and existential guided approach to understanding how parents embodied the experience of advocacy through describing four guides of reflection; body, space, time and relation. Body is how the mother physically embodies the experience such as through emotion. Space describes physical places in where mother's advocating takes place, such as within the school, classroom, and home. Relationships are who the mothers frequently describe when 
discussing the advocacy process, such as with their children and educational staff. Finally, time is defined as the way mothers discuss advocacy through past, present and future. Each participant interview transcript was also individually analysed for emergent themes, all transcripts were compared for similarities and differences within the questions asked (based on the existential guided approach) and interviews were also analysed for salient or revelatory phrases and idioms that participants used throughout their interviews that contributed to the overall understanding of what it is be a mother of a complex child and be advocating for that child within the special education sector. 


\section{Adding Disney to the Research}

During the thesis writing process, the Author decided to give pseudonyms (Disney cartoon characters) to each participant and their children as a way to organize and recall specific events within the writing process, remember which pseudonym belongs to which family unit, and as a way to ensure the confidentiality/anonymity of the participants in the study. The choosing of the pseudonym became a fun, creative, and engaging process in itself while writing the final thesis, as each cartoon character was carefully and specifically chosen to represent the participant. Pseudonyms of the participants were selected based on personality of the Disney cartoon character, physical attributes, storyline of the characters, and over-arching themes found within the analysis of each participant interview. Disney Character pseudonyms were not limited to human characters but to animal characters as well, such as to help maintain confidentiality (one cannot guess a participant solely based on physical attributes with animal characters, and not all assigned Disney characters to family units constituted exclusively human Disney characters or just Disney animal characters, which added variability and more anonymity to the process). While there were various criteria used to match a Disney pseudonym to the participant, in order to maintain anonymity, not every participant was given a pseudonym based on the same criteria. As an example, the character Ursula was chosen to represent a participant based on both the character's and participant's personality while another participant was given the pseudonym of Ariel based on some of the similar themes found within the story line of the movie The Little Mermaid (1989) and some of the themes found within the participant's particular interview analysis (the bad daughter theme).

One of the structures of thesis writing, and in particular when writing the finding sections of qualitative research, are the use of titles and subtitles which are often used as road signs to illuminate an upcoming theme, or particular findings that foreshadow what is about to be discussed (Munnawer, 2015). Within phenomenological research, Van Manen (1990) suggests that researchers should organize the writing up of the findings section of the study thematically so that essential aspects of the phenomenon might be illuminated in a way that permits the reader to understand how the participants have experienced and embodied the phenomenon under investigation as a whole. The use of subtitles within the write up of a study or thesis lets the reader move through each theme of the findings section in an organized way while still giving the reader an ability to gather an overall understanding of what it is to experience the specific phenomenon, such as in this case, the experience of advocating for complex children within the special education system and in particular the IEP process. Moving through these subtitles or themes throughout a thesis allows the reader a smooth transition from one idea to the next, just as a visitor moving from each world showcase at Epcot allows for a smooth transition from experiencing one culture to the next but still experiencing the park as a whole.

The author also chose to use creativity within the findings section of her thesis by giving creative subtitles to illuminate the upcoming themes that would be discussed based on the findings of her research. The use of creative subtitles allowed the author to describe her results in an organized way and created a sort of road map to the overall themes that emerged from the study. The author, sticking with the motif of Disney, chose to implement the unconventional approach to her thesis by using song titles from Disney movies and television shows as a way to organize her research. The process began by separating her findings section of the thesis into two parts; the website analysis data set and the interview data set. After analysis of each data set, emergent themes/findings were written down on a separate piece of paper as a quick reference guide for the writing process as a way to help organize the results, and as a coping strategy to aid in executive functioning processes such as with memory recall, planning, anticipating what section would come next, and as a way to help with writing smooth transitions from one idea to the next. The use of Disney song titles helped the author to organize the transition of one theme/finding to the next and consolidate her thoughts in a coherent manner. Finding the 'right' song to describe the main themes that emerged from the research analysis, not only contributed to a more engaged writing process, but allowed for the author's creative thinking to shine through in an otherwise orthodox and predictable thesis structure that tends to follow a particular academic design. While the activity of finding the "right" song to represent the upcoming theme that would be described in each section was a long process, and contributed to an overall longer time period in terms of writing the thesis, the creative strategy became a source of fun, and allowed the author to stay focused and engaged in an academic practice that is often tedious, tiresome, and requires an inordinate amount of attention and self-regulation.

\section{Disney Subtitles and Thematic Foreshadowing}


The interview data set had several themes that emerged due to the use of the holistic and embodied analysis of the mothers' experience of advocacy within the IEP process (body, space, time and relation). One theme that emerged within the analysis of how mothers described their experience of advocating physically (the body) was the concept of Autism as seen as an invisible disability. Many of the mothers described that having children with Autism could be difficult within the school system, because there are no physical attributes that are associated with the disorder. Therefore, the author chose the song title "Things are not what they Appear" (Pochahontas, 1995) as the subtitle to represent the upcoming theme that not every child experiencing disability has physical attributes attached to a given disorder, and this can make it difficult for others to remember or recognize the child's needs.

The analysis of idioms within the interviews led to many interesting themes; however, one particularly fascinating theme that emerged was that mothers often referred to themselves as predatory animals when discussing their experiences of advocacy and used these idioms as a way to express their need to protect their child such from the school such as through perceived or actual experienced maltreatment, and issues accessing needed accommodations. Mothers compared themselves to such predatory animals as hawks as a way to describe their need to keep an eye out on what was occurring within the school, or a bear as a way to describe the fierce protectiveness they felt for their child, and the need to speak for those children who could not speak for themselves. The Disney song "Everybody wants to be a cat" (The Aristocats, 1970 was subsequently chosen as the subtitle to represent the upcoming theme of mothers referring to themselves as animals within the findings.

In one of the individual transcript analyses, the Disney song title "Never Smile at a Crocodile" (Peter Pan, 1953) was used as the subtitle to illuminate the upcoming theme that emerged from one of the participants who often described a distrust towards school officials. The participant often expressed the feeling that she needed to tread lightly in meetings through her interactions with staff, such as the way she spoke to them, how much she disagreed or agreed with plans or goals for her child, and in anticipation of any issues that might arise within the meetings. The particular participant struggled with her relationships with the school staff. On one hand she expressed her desire to work as an equal team member but on the other hand she often communicated her fear that if she spoke the wrong way or disagreed with the staff, that the school could call child protective services on her. Therefore, smiling at the crocodile was equated to the power differential between the mother and the school, and the belief that while the staff may appear nice in meetings, at any moment they could turn, so there was a real distrust of saying or doing the wrong thing. It illuminated the experience of how advocacy could be a tricky process where the benefits and costs must frequently be weighed.

In the data set that analysed ease of access to rights-based information on schoolboard websites, Disney song titles were also used to foreshadow upcoming themes that emerged. One of the over-arching themes found within the school board website research was that rights-based information about the IEP process was almost always challenging to find. On average a parent was found to have to click on average 10 times and navigate through an average of 62 possible tabs or links before being able to find information that informed parents about their rights and their child's rights. "Just Around the Riverbend" (Pocahontas, 1995) was chosen as the subtitle as a way to describe and illuminate the process of navigating and locating rights-based information within the school board websites. The song title (subtitle) was meant to be an ironic foreshadowing of the often, problematic inability to easily access rights-based information on school board websites, and the inordinate length of time it took parents to navigate and find the information. Parents would most likely be hoping that just around the bend they would locate the documents that they were looking for!

The song title "Dig a Little Deeper" (The Princess and The Frog, 2009) was also used as a subtitle to describe the findings within the website analysis which found that links on the website for rights based information was often found embedded within large amount of text on the webpage (and often a shade lighter than the surrounding text), and which could be easily missed, had the parent had not been reading the information provided on the webpage. Other times, information was frequently found at the very bottom of the page, which meant that if parents did not scroll all the way to the bottom of webpages (some which could be quite long, or some designed to appear as if no information existed beyond what could be originally viewed when opening the link on the page) the parent would miss the information. Other times links to rights-based information was found in font that was slightly smaller and in colored text slightly lighter than the surrounding text, making the visibility of the link to rights-based information hard to find. Parents had to dig deep so to speak to find the provided rights-based information, while info that offered simple 
definitions or benefitted school boards (i.e. did not provide rights-based information) was easily accessible and visible and did not require the parent to dig. Unlike Epcot where there is a seamless movement from one world showcase to the other, parents could not seamlessly move from one section to the next within the school board websites to learn about information they were seeking (IEP process).

\section{DISCUSSION}

The use of learned creativity and in particular incorporating Disney song titles as subtitles to inform the reader of upcoming themes found within the research study or used as ironic humor as a way to distract from sometimes uncomfortable events or findings of the research clearly broke from the traditional and hegemonic traditions of thesis writing. While distinctly unconventional, it allowed the author the ability to accomplish two things; firstly, it became a type of coping strategy that contributed to the engagement of the writing process and the ability for the author to complete her thesis, and submit it within the allotted time lines. Secondly, the ability to use creative freedom and incorporate her affinity for Disney into her thesis (such as in the use of the subtitles) enabled her to establish and present her mastery and knowledge/understanding of her research and the emergent themes in such an effective way, that had she not been given the freedom to do so and was required to follow the strict writing procedures often required of graduate students in their academic work, her expertise may not have been adequately showcased. This example illuminates the need for academic institutions and graduate supervisors to allow students to move from more traditional methods of academia to incorporating alternative mediums or methods in order to enable students with diverse learning needs alternative solutions and opportunities to exhibit their knowledge in the same way that students without learning disabilities are able to do.

Finding creative ways to keep students engaged with their academic work, such as through the EPCOT Approach is important and in particular for those students who have diverse learning needs. The freedom of creativity given to the author is a demonstration of how particular social and cultural discourses on normativity in specific spaces can impact an individuals' success. In this case, allowing for creativity and alternative strategies that strayed from typical academic norms and expectations in writing, provided an environment in which the author's learning impairments went unnoticed, and who was able to successfully complete her Master's program. Alternatively, had she been prohibited from employing creativity within her writing, the academic environment through lack of accommodations may have caused her learning impairment to become disabling and thereby potentially contributing to an inability to successfully complete her program. It is important to recognize how academic environments and expectations can have the potential to create disability in individuals who might not otherwise be labelled as such given the appropriate supports and accommodations.

Wendell (1996) suggests that non-disabled people often receive help or accommodations in different social setting, however this is often taken for granted and not considered to be help, because it's offered to citizens who fit the social discourse on hegemonic normalcy. She notes that it is only when individuals require a different kind or amount of help/accommodations that it is viewed as help at all. In classroom settings for example, teachers may provide 'help' to non-disabled students by orally giving a lesson or instructions on how to complete an assignment, however some students may also require written instructions/lessons in order to accommodate executive functioning deficits. While orally giving non-disabled students instructions/lessons may not be viewed as help, the accommodation to have to also provide a written format would be considered help because it requires a different kind of instruction than what the rest of the class is receiving.

It is important for educators and academic institutions to understand how failure to accommodate or allow students with different impairments to stray from assumed normative practices creates otherness and disability, intentionally or not, by ignoring and ultimately denying the experiences of individuals with disabilities and impairments within academic institutions. Allowing even for even small changes to orthodox practices such as incorporating creativity in thesis writing, are small steps in which the impairment can stay away from becoming disabled.

\section{FUTURE IMPLICATIONS}

While this particular paper examines the use of incorporating creativity and the EPCOT approach to graduate students and thesis writing, this approach and use of creativity can be used at all levels of learning for children and youth who 
may be neuro-diverse and who may have learning disabilities or difficulties. Using this approach can have the potential to have a significant impact on childhood academic success. While the author incorporated her own interest in Disney into her work, teachers can encourage children to incorporate their own interests into their work in order to foster attention, focus, excitement, and engagement within the learning process. Students often find writing task topics and requirements ambiguous or difficult within the classroom, and this can contribute to poor performance and engagement within the classroom, in particular for those students who may have diverse learning needs (Phan, 2009). Encouraging students to incorporate or write about their interests within a specific subject matter, can help children become more engaged within their learning and completion of tasks. Allowing children and youth to incorporate small pieces of creativity within their academic work can give a greater holistic view of children's knowledge acquisition and application, and how children experience learning in diverse ways. Like EPCOT each student has their own authentic experience of learning, and how they acquire knowledge in any given environment or spaces (home, school, and internet). While these spaces are different (like the world showcases at EPCOT) they all contribute to an overall engagement with and absorption of knowledge. Encouraging children to share these ideas and knowledge through a variety of mediums (verbal, written, drawing) can create a creative and inclusive environment that encourages creativity and engagement within the learning process, particularly for those who may have diverse learning needs.

\section{AUTHOR BIOGRAPHY}

Michelle Janzen is a Ph.D. student attending Brock University, within the Child and Youth studies department. Her research focuses are in examining parental advocacy for children with complex needs within the special education system, special education policy, international policy on inclusion for individuals with disabilities, and how international policy on disability is perceived and implemented within the global south. As a mother of a child with complex needs, her passion in the study of disability and rights-based policy has been fueled by her own experiences advocating for her child.

\section{REFERENCES}

Beltzer, A. \& Ross-Gordon, J. (2011). Revisiting debates on learning disabilities in adult education. New Directions for Adults \& Continuing Education, (132), 75-84

Chenail, R. (2004). When Disney meets the research park: Metaphors and models for engineering an online learning community of tomorrow. The Internet and Higher Education, 72(2) 107-121.

Couzens, D., Poed, S., Katooka, M., Brandon, A., Hartley, J., \& Keen, D. (2015). Support for students with hidden disabilities in universities: A case study. International Journal of Disability, Development and Education, 62(1), 24-41

Disney, W. (Producer) \& Gernonimi, C., Jackson, W., Luske, H. \& Kinney, J. (Directors) (1953). Peter Pan, USA, Walt Disney Studios.

Eladi, S. \& Batdi, V. (2016). The effects of different applications in creativity regarding academic achievement: A meta-analysis. Journal of Educational and Training Studies, 4(1), 170-179.

Farmer, J. L., Allsopp, D. H., \& Ferron, J. M. (2015). Impact of the personal strengths program on self-determination levels of college students with LD and/or ADHD. Learning Disability Quarterly, 38(3), 145-159.

Fichton, C. S., Heiman, T., Jorgenson, M., Nguyen, M. N., Havel, A., King, L., Budd, J. \& Amsel, R. (2016). Theory of planned behaviour predicts graduation intentions of Canadian and Israeli postsecondary students with and without learning disabilities/attention deficit hyperactivity disorder. International Journal of Higher Education, 5(1), 208-219.

Grieve, A., Webne-Behrman, L., Couillou, R., \& Sieben-Scnieder, J. (2014). Self-report assessment of executive functioning in college students with disabilities. Journal of Postsecondary Education and Disability, 27(1), 19-32.

Hanan, E. \& Bright, D. (2016). Writing a thesis differently. International Journal of Qualitative Studies in Education, 29(5), 731743.

Luna, C. (2002). Learning from diverse learners: (Re) writing academic literacies and learning disabilities in college. Journal of Adolescent \& Adult Literacy, 4(7), 596-605

McVey, D. (2008). Why all writing is creative writing. Innovations in Education and Teaching International, 45(3), $289-294$.

Munnawer, S. (2015). Thesis writing: An art or skill of scholar? European Scientific Scholar, 11(17), 1857-1881.

O'Grady, E. (2016). Research as a respectful practice: An exploration of the practice of respect in qualitative research. Qualitative Research in Education, 5(3), 229-254.

Phan, L. H. (2009). Strategic, passionate, but academic: Am I allowed in my writing. Journal of English for Academic Purposes, 8(2), 134-146.

Reiff, H., Gerber, P. \& Ginsberg, R. (1993). Learning to achieve: Suggestions from adults with learning disabilities. Journal of Postsecondary Education \& Disability, 10(1), 11-23.

Stegemann, K. (2016). Learning disabilities in Canada. Learning Disabilities: A Contemporary Journal, 14(1), 53-62. 
Van Manen, M. (1990) Researching Lived Experience: Human Science for an Action Sensitive Pedagogy. Albany: State University of New York Press.

Villmoare, A. \& Stillman, P. G. (2002). Pleasure \& politics in Disney’s utopia. Canadian Review of American Studies, 32(1), 81105.

Walt Disney Pictures (Producer), Clements, R. \& Musker, J. (1989). The Little Mermaid. USA, Silver Screen Partners IV.

Walt Disney Pictures (Producer) \& Goldberg, E. \& Gabriel, M (Directors) (1995). Pocahontas. USA, the Walt Disney Animation Studios.

Walt Disney Pictures (Producer) \& Clements, R. \& Musker, J. (Directors) (2009). The Princess and the Frog. USA, Walt Disney Animation Studios.

Walt Disney Productions (Producer), Reitherman, W. (Director) (1970). The Aristocats. USA, Buena Vista Distribution.

Wendell, S. (1996) The rejected body: Feminist philosophical reflections on disability. Routledge, Taylor \& Francis Group: New York, London. 